\title{
O FUNDAMENTALISMO RELIGIOSO: O USO DA INFORMAÇÃO E A CONTRAINFORMAÇÃO NUMA SOCIEDADE QUE VIVE EM REDES DE COMUNICAÇÃO
}

Rogério Neves

Resumo: A discussão sobre o fundamentalismo nos leva a pensar que existam uma infinidade de contornos para defini-lo. Neste texto, as reflexões partem do fundamentalismo religioso, consciente da complexidade e dificuldade da questão. A religião como um termo técnico sugere que é possível pensar em vários fatos de formas diferentes. $\mathrm{O}$ fundamentalismo religioso pode ter também distintos contornos e situações que nos fazem acreditar que há outros tantos fundamentalismos que precisamos descobrir, discutir e ponderar conforme se investigam as suas manifestações históricas. Entre a objetividade e a subjetividade da religião, discutir o fundamentalismo religioso em pleno século XXI é também pensar que a nossa incontestável situação de existência humana não esteja pautada simplesmente no plano físico, e que hoje enfrentamos uma realidade pautada em distâncias materiais estruturadas num mundo que vive em redes de comunicação.

Palavras-chave: Fundamentalismo, Religião, Informação, Comunicação.

Abstract: The discussion of fundamentalism lead us to think that there are innumerable contours to define it. In the text, the reflections depart from religious fundamentalism, aware of the complexity and difficulty of the issue. Religion as a technical term suggests that it is possible to think of several facts in different ways. Religious fundamentalism may also have different outlines and situations that make us believe that there are so many fundamentalisms that we need to discover, discuss and ponder as their historical manifestations investigaged. Between the objectivity and the subjectivity of religion, to discuss religious fundamentalism en the twenty century is also to think that our incontestable situation of human existence is not simply based on the physical plane, today we face a reality based on material distance structured in a world that lives in communication networks.

Keywords: Fundamentalism, Religion, Information and Communication.

\section{Causas e efeitos históricos}

No início do século XXI, com os atentados de 11 de setembro de 2001, todas as reflexões sobre medidas de segurança internacionais precisaram ser revistas, pois não era possível que os mais rigorosos protocolos de segurança em aeroportos e outros ambientes teriam sido inócuos. 
Grupos de militantes religiosos passaram incólumes as fronteiras de proteção dos Estados Unidos da América - EUA, o país com os mais altos sistemas de segurança pública do mundo.

Entre as inúmeras discussões que se estenderam após aquele momento triste da história mundial, reflexões pontuais sobre o uso das tecnologias e principalmente sobre a informação e comunicação estiveram no centro dos debates em relação às ameaças que o fundamentalismo religioso poderia trazer com essas inovações.

Sabe-se, por exemplo, que uma das primeiras medidas tomadas após 11 de setembro foi a rigidez e acompanhamento nas pesquisas realizadas pelos usuários de bibliotecas, arquivos, centros de documentação e outros espaços públicos de pesquisas nos EUA, pois muitos dos militantes religiosos naquele momento utilizaram esses espaços como locais de reuniões, estudos e praticamente funcionaram como Quartéis Generais para aplicar suas estratégias de ação "terrorista".

Mas, antes de caminhar pelas reflexões mais pontuais sobre o uso da informação e o fundamentalismo religioso, vale voltar um pouco no século XX e compreender que essa realidade vivenciada no século XXI de alguma forma era projetada por vários historiadores. Eric Hobsbawn foi um deles, e apontava os desfechos do século XX indicando que o fundamentalismo religioso também traria impactos para o novo milênio.

O Breve Século XX foi uma era de guerras religiosas, embora os mais militantes e sanguinários de seus religiosos bebessem nas ideologias seculares da safra do século XIX, como o socialismo e o nacionalismo, cujos equivalentes divinos ou eram abstrações ou políticos venerados como divindades. É provável que os extremos dessa devoção secular já estivessem em declínio mesmo antes da Guerra Fria, incluindo os vários cultos de personalidade políticos: ou melhor, haviam sido reduzidos de igrejas universais a um punhado de seitas rivais. Apesar disso, sua força estava não tanto na capacidade de mobilizar emoções próximas da religião tradicional, mas na promessa de dar soluções duradouras aos problemas de um mundo em crise. (HOBSBAWN, 2003; p.541-542)

São muitas as variáveis que apontam essa guinada do fundamentalismo religioso no mundo que se tornou global pelos caminhos da tecnologia da informação e da comunicação; e que ao mesmo tempo ampliou suas fontes de tensão, ora envolvendo o mercado internacional global, ora atingindo a estabilidade social das nações. No continente europeu é possível afirmar que os erros cometidos no passado pelos colonizadores europeus e as inúmeras intervenções no Oriente Médio, assim como na África, repercutiram de maneira violenta como um todo na Europa e hoje as novas gerações sofrem com esses desdobramentos.

Há também a tese de que após 11/09 a declaração dos EUA na luta contra o terrorismo deu crédito a todas as nações que encontrassem terroristas, e isso significou de alguma forma uma 
espécie de banalização do termo "terrorismo". Amplificou a ideia apontada neste texto de movimento contrainformação, ou seja, do outro lado os "inimigos" dos terroristas virariam todos aqueles que não partilhassem dos mesmos preceitos religiosos.

Para Saint-Pierre,

O conceito de "terrorismo" é um dos mais usados por políticos, jornalistas e um dos menos refletidos. Na verdade, o escopo semântico desse conceito goza de uma elasticidade assombrosa que satisfaz as necessidades de todo o político para eliminar oponentes [...] o conceito de "terrorismo" desde muito antes do 11/09 funcionou como um imã para "especialistas" oportunistas. Ele foi usado amplamente durante ditaduras militares para se referir aos movimentos de resistência armada, antes disso foi empregado pelo governo francês para se referir ao movimento de libertação da Argélia. Depois de 11/09, quando os EUA facilitaram créditos para a luta contra o terrorismo, todos encontraram terroristas em seu próprio quintal. (SAINT-PIERRE, 2016; p.2)

Vale pensar que, homogeneizar como terroristas todos aqueles que se manifestam contra uma forma de governo ou lutam para manter sua ideologia seja ela religiosa ou não, acaba por enfraquecer o próprio combate contra de fato aqueles que agem estrategicamente, ou com o intuito de causar o terror. Pois nem sempre o terrorista quer o poder, e qualificar grupos políticos, oposição ou guerrilheiros com essa chancela parece ter sido um ato constante em diversos países, inclusive na América Latina.

\footnotetext{
Assim, o presidente da Colômbia, Uribe, mudou o apelativo de "narcoguerrilha" para "narcoterrorismo" para se referir às Forças Armadas Revolucionárias da Colômbia Exército Popular. No Peru, o presidente Toledo marcou movimentos indígenas ambientalistas também como "terroristas". No Brasil, o ministro da Reforma Agrária do governo Fernando Henrique Cardoso - FHC, Raul Jungmann, tentou enquadrar o Movimento dos Trabalhadores Rurais Sem Terra - MST como grupo "terrorista".(p.2)
}

Outras discussões se desdobram a partir dessas reflexões e certamente é preciso ter clareza que ao definir determinadas lutas, de determinados grupos como "terroristas" é colocada em xeque toda a história de legitimidade desses grupos, o que enfraquece o diálogo nos países que se dizem democrático e respeitam a pluralidade de opiniões e manifestações.

\section{O fundamentalismo religioso e a conectividade}

Quando a questão do terrorismo aproxima-se do mundo religioso, outras variáveis precisam ser colocadas em discussão, uma vez que, em meio ao mundo globalizado onde as consequências do desemprego se dão em alta escala e o reflexo desse infortúnio leva milhares de pessoas para o 
trabalho informal ou a imigração contínua e desse modo os choques culturais acontecem sistematicamente, o resultado inicial é o crescimento da intolerância que pode vir como uma espécie de personificação manifestada na religião, no estrangeiro, na língua, nas características físicas, etc.

Juntamente com o crescimento da ansiedade, fruto da degradação crescente do mundo trabalho - aumento do desemprego e da informalidade, em conjunto com a queda da renda média -, o medo e a intolerância têm aumentado substancialmente neste início de século. $\mathrm{O}$ outro - personificado pelo diferente, pelo estrangeiro, ou pelo mulçumano - passa a ser potencialmente um inimigo que pode fazer mal, seja o vizinho estranho, ele pode ser um terrorista, seja o imigrante que fazia um trabalho que você não queria, mas que, agora, pode ser a sua alternativa de trabalho. (DUPAS, 2005; p.207)

Talvez o preceito da tolerância em tempos de muita impaciência reforce a tese de que aceitar o outro com suas diferenças, principalmente culturais, tenha levado e elevado o número de manifestações preconceituosas no mundo todo, assim como o racismo ou o preconceito religioso. $\mathrm{O}$ desdobramento desse quadro é uma sociedade que replica manifestações preconceituosas nos mais variados espaços e infelizmente temos visto o crescimento de atitudes preconceituosas em ambientes que deveriam ser locais para minimizar as diferenças, como é o caso das escolas e universidades que precisam discutir diariamente questões relacionadas ao bullying.

Esses espaços de formação e educação são muitas vezes utilizados pelos terroristas pela vulnerabilidade e facilidade com que esses grupos conseguem mostrar sua brutalidade como forma de atingir seus objetivos. Nos EUA principalmente, é muito recorrente esse tipo de situação. Nesse caso não são apenas os terroristas os principais agentes desses ataques. Há muitos simpatizantes que de alguma forma utilizam as falsas premissas religiosas para agir e causar o terror. Há inclusive interpretações equivocadas das religiões, como é o caso de atos em nome do Islamismo.

Todos utilizam apelo islâmico com interpretações distorcidas do Corão e as mídias sociais na internet para conseguir adeptos; todos pregam o objetivo final de mudar o estado das coisas criando uma nova sociedade (islâmica) devidamente protegida do modo de vida e dos valores "mundanos" e "infiéis" dos ocidentais, mostrados como os grandes responsáveis pelos problemas existentes nas regiões em que atuam. Mas, principalmente, utilizam o radicalismo, apoiado numa causa ideológica e religiosa, por conta do qual os meios justificam os fins. Ou seja, não importa o grau de violência a ser utilizado desde que ataque os supostos "inimigos" onde quer que eles estejam. (AGUILLAR, 2016; p.35)

É possível constatar que os terroristas já compreenderam o poder da sociedade em rede. Ou seja, para ser visto não basta explodir carros e prédios, é preciso impressionar com a rapidez que a 
informação circula nas redes sociais. Com isso, é possível cooptar admiradores, pois o efeito cirúrgico das informações em tempos de guerra já foi assimilado pelas Nações e também pelos fundamentalistas religiosos.

A informação e a contrainformação nesse caso surgem quase na mesma proporção, pois o acesso aos fatos independe do poder de comunicação, mas da rapidez e precisão com que se mostra um fato, um acontecimento. No caso de eventos com teor de destruição em massa, como guerras e atentados, o ideal é que seja instantâneo, como afirma Castells, ao discutir a sociedade em rede.

\begin{abstract}
Uma vez que a luta armada e a provável ameaça de recorrer a ela continuam no centro do poder estatal, desde o fim da guerra do Vietnã, os estrategistas têm se esforçado para encontrar meios de ainda fazer guerra. Apenas nessas condições o poder econômico, tecnológico e demográfico pode ser transformado em dominação de outros Estados, o jogo mais antigo da humanidade. Os países democráticos desenvolvidos chegaram a três conclusões em relação às condições necessárias para tornar a guerra de certa forma aceitável à sociedade.
\end{abstract}

- Não deve envolver cidadãos comuns, portanto deve ser feita por um exército profissional, de modo que a convocação obrigatória fique reservada para circunstâncias realmente excepcionais, julgadas improváveis;

- Deve ser curta, até mesmo instantânea para que as consequências não subsistam, consumindo os recursos humanos e econômicos e suscitando questões e justificativas para a ação militar;

- Deve ser limpa, cirúrgica, com destruição até mesmo do inimigo, mantida dentro dos limites razoáveis e escondida ao máximo possível da visão pública, com a consequência de ligar intimamente manuseio da informação, formação de imagem e prática de guerra. (CASTELLS, 1999; p.481-482)

Grupos de militantes religiosos, ao compreenderem essa situação, começam a agir em oposição aos três preceitos apontados por Castells (1999), ou seja, suas estratégias estão pautadas em seguir justamente na direção contrária do anonimato e da instantaneidade: começam a envolver civis inocentes em suas ações. Cada atentado e manifestações são planejados a médio e longo prazo, tendo sempre a ideia de efeito surpresa. Por último, o que mais importa nessas ações é mostrar o poder de destruição, implementar a sensação de insegurança e medo, além de apontar para o mundo, ou para o maior número de pessoas, sua força e poder de informação.

\title{
Poder, religião e o crime organizado
}

Ao considerar que o poder sempre esteve no centro das discussões sobre as manifestações terroristas de cunho religioso, a exemplo do que se tem visto no Estado Islâmico - EI, essas manifestações de rebeldia como determinação social têm sido uma espécie de chamariz para que 
jovens do mundo todo se identifiquem com suas causas. Seguindo nessa direção, é possível afirmar que certamente seja uma das situações mais delicadas e que mais precisará ser combatida no contexto da guerra contra o fundamentalismo religioso.

Não se pode negar que há outros fatores que interferem diretamente nesse contexto e que precise de alguma ponderação nas reflexões apontadas aqui. Fala-se da facilidade com que esses terroristas conseguem adquirir seu armamento, explosivos e outros materiais bélicos em qualquer lugar do mundo. Pois há um crime organizado que mantém a venda de armas de alta destruição e isso também fomenta o poder bélico desses grupos, uma vez que os alvos mudaram.

Os atentados de grande proporção acontecem em locais onde há aglomeração de pessoas, como estações de trens e metrôs, casas de shows, estádios e praças públicas. A equação é simples: armas de alta precisão e destruição são letais em grandes conglomerados humanos. Dessa forma a luta das nações é tentar desestabilizar um comércio ilegal de armas que só cresce e amplia o poder de destruição daqueles que acreditam apenas na sua verdade. Para muitos especialistas essas ações são simples e geram resultados catastróficos.

\footnotetext{
Esse tipo de atentado é muito mais simples de preparar e executar e mais difícil de ser descoberto pelos órgãos de inteligência, mas causa o mesmo impacto. Há uma enorme facilidade de se adquirir armas e explosivos no mercado negro operado pelo crime organizado e o poder destrutivo dos fuzis é grande quando empregados de surpresa contra pessoas reunidas em locais de trabalho, casas de espetáculos, estádios de futebol ou bares.

Os alvos também mudaram[...] O terrorismo do século XXI ataca locais com algum significado paras os terroristas como símbolo do poder (World Trade Center, Pentágono) ou da vida infiel (bares e casas de show) ou que permitem atingir grande número de pessoas (meios de transporte Londres e Madrid) e, com isso, o impacto, a publicidade ajuda no objetivo maior que é espalhar o medo e o sentimento de insegurança. (AGUILAR, 2016; p.36)
}

O que se pode afirmar com essa nova realidade mediante aos muitos atentados é que as ações terroristas geram outros atos ainda mais perigosos. Uma espécie de contrarreação baseada em manifestações que estavam adormecidas, como o caso dos xenófobos que saem à rua com seus cartazes ofensivos, são o crescimento do preconceito em relação às comunidades islâmicas e o neonazismo, que têm encontrado força na Europa Ocidental.

Ao mesmo tempo há um aumento do uso da força por parte dos Estados, vigilância reforçada nas fronteiras, rigor em portos, aeroportos e outros locais por onde possam entrar imigrantes clandestinos. Crescem também outras manifestações políticas baseadas na intolerância, no preconceito, com representantes oficiais e partidos que defendem tais ideologias. 
Parte desse problema enfrentado pelas nações pode ser creditada ao descumprimento de políticas internacionais pelos diversos grupos que não aceitam como valores e verdades convenções instituídas nos séculos XIX e XX, como as de Haia e Genebra. Os Estados não conseguem negociar com grupos como o Estado Islâmico, que não aceitam valores que são comuns entre os países.

\section{Liberdade, religião e o mundo organizacional}

Outro ponto de destaque é a forma como a sociedade tem se organizado e construído seu espaço de participação e liberdade, que hoje tem encontrado vazão nos ambientes online de discussão. Esses ambientes são muitas vezes mediados por grandes corporações, que se apropriam do indivíduo e o torna um consumidor que doa seus direitos a um sistema que pode ser chamado de corporativo, circundado de anúncios e logomarcas, ou seja, grandes empresas com um simples objetivo: vender e transformar o cidadão num comprador de ilusões. Dessa forma a sociedade civil começa a perceber sua impotência em resolver problemas coletivos da humanidade, como a fome, o preconceito, a miséria, as questões relacionadas ao meio ambiente e também assuntos voltados ao respeito religioso ou sincretismo religioso, à mercê daquilo que Gilberto Dupas (2005) chamou de Sociedade Organizacional.

\footnotetext{
$\mathrm{Na}$ teoria política clássica, incorporada ao inconsciente coletivo das sociedades, o espaço público era equivalente ao espaço da liberdade dos cidadãos que exerciam sua participação crítica na gestão dos assuntos comuns, sob o princípio da deliberação; era um espaço que se opunha, portanto, ao espaço privado regido pela dominação do poder [...] Passamos de uma sociedade política a uma sociedade organizacional, entendida como uma sociedade sistêmica e tecnocrática que legitimaria os direitos da pessoa; a liberdade, portanto, passou a ser defendida de maneira totalmente privada. A identidade política universalista, à qual correspondia o conceito de cidadania, diluiu-se e fragmentou-se, permitindo a proliferação de identidades coletivas não somente particulares, mas parciais e truncadas. (DUPAS, 2005; p.175-176)
}

Ao se organizar para defender a liberdade de maneira privada, a sociedade civil encontra em muitos ambientes força para combater essa ideologia do mundo privado organizacional. Muitos são seduzidos pela coletividade da religião, de movimentos paramilitares, e nesses espaços é possível a ideia de uma discussão "pública" e supostamente de participação política, mesmo que no cerne desse cenário o que pode restar é uma espécie de exploração de poderes hegemônicos que se apropriam dos benefícios que vêm dessas novas percepções sociais. 
Pode-se afirmar então que há uma desmobilização global em meio a tanta conectividade. A preocupação dos países está na luta pela integração econômica e desse modo as lutas sociais ou a possibilidade de interação e integração entre grupos sociais internacionalmente capazes de trabalhar em cooperação ficam fragilizadas pela falta de espaço e capacidade de se organizarem de forma global, numa economia que reduz os incentivos e consequentemente o engajamento cívico de grupos que poderiam mediar os muitos conflitos sociais, étnicos e religiosos. Isso pode ser entendido como uma desintegração social à custa da integração econômica, como discute RODRIK (2011)

\begin{abstract}
Se não forem bem administradas, as pressões sociais desencadeadas pela integração econômica global provavelmente resultarão em uma má economia e em um mau governo. Não apenas porque a globalização destaca e exacerba as tensões entre os grupos, o que realmente ela faz, mas também porque reduz a disposição dos grupos internacionalmente móveis para cooperar com outros na resolução de desacordos e conflitos [...]

Portanto, a globalização desfere um duplo golpe na coesão social - primeiro, exacerbando o conflito sobre as crenças fundamentais relacionadas à organização social; depois, enfraquecendo as forças que normalmente militariam em prol da resolução desses conflitos mediante debates e deliberações nacionais. (p.108 - 109)
\end{abstract}

O resultado desse cenário mostra que existe um mercado internacional que exerce um poder, muitas vezes sem a devida legitimidade. Amplia as tensões sociais existentes na sociedade e dificulta o trabalho que poderia ser realizado junto às comunidades locais.

Vale acrescentar a esse panorama que a discussão sobre o fundamentalismo não significa que exista exclusivamente o fundamentalismo religioso; Ele pode ter distintos contornos e situações que nos faz acreditar que há outros tantos fundamentalismos que precisamos descobrir, discutir e se for possível, ponderar nosso posicionamento em relação às atribuições do fundamentalismo religioso associadas a posições radicais ou de violência. Pois é possível enxergar em nossa sociedade que há inúmeras formas de fundamentalismo.

De modo geral quando se fala em fundamentalismo, é no fundamentalismo religioso que se pensa. Há, porém, outras formas de fundamentalismo: o fundamentalismo político, o fundamentalismo cultural, o fundamentalismo econômico, por exemplo. Joseph Stiglitz, Prêmio Nobel da Economia, referindo-se à política econômica seguida pelo FMI no quadro da Globalização, fala de "fundamentalismo Neoliberal". (BORGES; 2010, p. 74)

Mediante essas afirmações pode-se caminhar para outros fundamentalismos a fim de compreender os aspectos de seu viés religioso no mundo. Essa expansão etimológica do pensamento para novas reflexões sobre o tema abre mais possibilidades para que nossa percepção 
não fique apenas no contexto da religião, mas permeie outros campos do conhecimento ou que se relacione com outras temáticas que interferem de alguma forma nesse cenário. Uma delas, a cultura da contestação, teve sua explosão no final do século XX em decorrência das mudanças políticas internacionais, da influência do pensamento mais liberal sobre os costumes, dos modos de produção na indústria e também por influência da ampliação dos meios de comunicação e informação.

\begin{abstract}
Nas últimas décadas do século XX, o mundo viveu uma descomunal crise em decorrência, sobretudo, dos efeitos colaterais da Guerra Fria. Nos quatro cantos do mundo, estabeleceuse uma forte tensão entre aqueles que, de um lado, queriam mudar os rumos da política, das relações sociais, dos hábitos e costumes e pautavam tais mudanças pelo sentido político que elas adquiriam em contexto revolucionário, e os que se opunham a mudanças radicais por terem seus interesses diretamente ameaçados. (OLIVEIRA; 2004, p. 17)
\end{abstract}

Essa contestação em países como o Brasil veio dos problemas sociais, estampados nas desigualdades econômicas visíveis, seguidas de políticas pautadas na repressão somadas aos problemas de uma população muito grande de analfabetos. Como consequência desse panorama de disparidades, o aumento do uso de drogas, a violência urbana e a exclusão social resultaram num cenário catastrófico que de alguma forma teve impacto na macroeconomia do país.

Ao mesmo tempo em que o mundo clama por mudanças de natureza política e social é possível perceber historicamente que por trás dessa cultura da contestação o que surgiu como elementos profundos de discussão foram pensamentos pautados na formação de identidade de muitos países.

\begin{abstract}
Em todas as culturas, o processo pelo qual a lei geral suplanta a lei particular faz-se acompanhar de crises mais ou menos graves e prolongadas, que podem afetar profundamente a estrutura da sociedade. O estudo dessas crises constitui um dos temas fundamentais da história social. Quem compara, por exemplo, o regime do trabalho das velhas corporações e grêmios de artesãos com a "escravidão dos salários" nas usinas modernas tem um elemento precioso para o julgamento da inquietação social de nossos dias. Nas velhas corporações o mestre e seus aprendizes e jornaleiros formavam como uma só família, cujos membros se sujeitam a uma hierarquia natural, mas que partilham das mesmas privações e confortos. Foi o moderno sistema industrial que, separando os empregadores e empregados nos processos de manufatura e diferenciando cada vez mais suas funções, suprimiu a atmosfera de intimidade que reinava entre uns e outros e estimulou os antagonismos de classe. O novo regime tornava mais fácil, além disso, ao capitalista, explorar o trabalho de seus empregados, a troco de salários ínfimos. (HOLLANDA; 1978, p. 102)
\end{abstract}

Essa realidade não é muito diferente nos dias de hoje em que o empregado continua sendo apenas um número, as relações humanas transformaram-se em relações virtuais, em que a luta de 
classe ou as lutas de ordem social precisam existir, se reinventar, ou desaparecerão em pouco tempo.

Dessa maneira, a cultura da contestação e da rebeldia toma força em ambientes privados, que muitas vezes estão sobrepostos ao universo da religião, e tal condição limita o sentido da liberdade, uma vez que existem hierarquias a ser respeitadas nesses ambientes, e não permite questionar ou mesmo criticar as autoridades estabelecidas.

De modo global o que existe hoje são ideias centralizadas em países desenvolvidos, e o restante do mundo reproduz esses ideais como grandes filiais administradas por seus governantes. $\mathrm{O}$ que está em jogo na verdade é a possibilidade de lutar por uma nova forma de viver: um mundo com mais igualdade entre os povos, com uma lógica menos competitiva e mais colaborativa, mais solidária; nessa realidade, a possibilidade da conectividade como uma dessas pontes para recuperar a essência humana. A condição de existência é tornar o ser humano um ser político, ativo, que colabore com a sociedade pelo diálogo, e não pela força e violência.

\section{A cultura da violência e a religiosidade}

Pautada na relação entre a obediência e a liberdade, o fundamentalismo religioso também tem suas raízes culturais na violência, como proposta de reorganização social condicionada a uma espécie de subversão da ordem na qual os princípios de uma autoridade religiosa estão à frente de preceitos ditos humanos, como o respeito às diferenças de qualquer natureza.

$\mathrm{O}$ ato de destruir tendo como objetivo a liberdade pode ser analisado como uma forma de rebeldia. Trata-se de uma obstinação em instituir valores pautados nas verdades que renascem de uma autoridade e supõem uma nova ordem instituída pela tradição e obediência aos códigos de conduta religiosos. Seu propósito é garantir a convivência e a tolerância entre os mais variados grupos.

Essa garantia não é certa, pois, de fato, o que se procura é um exercício de busca ao poder que se configura como uma identificação com o poder e por esse motivo tratar da questão entre religião e violência não é tarefa fácil e requer dos estudiosos cuidados mediante tamanha complexidade.

É demasiado complexa a relação entre a religião e a violência, referindo-se aqui apenas à dinâmica profunda que pode explicar a violência religiosa enquanto tal. Desde que toma consciência de si mesmo, o ser humano vive em sobressalto: independentemente da questão de saber se é mais dominado pela angústia ou pela esperança, está, de modo mais ou menos 
consciente, pela morte, constitutivamente confrontado com a possibilidade do nada - nunca mais ser. A consciência da morte tem o condão de revelar ao Homem de modo brutal e sem apelo a sua radical impotência: não é o seu próprio fundamento, em última análise não pertence a si e está permanentemente sob a ameaça de deixar de ser. Esta consciência provoca angústia, pois o confronto com o nada é simplesmente horroroso e laminante. (BORGES; 2010, p.27)

A complexidade se explica nesse caso por uma de nossas maiores inquietações: a morte. A violência religiosa que aniquila o outro por suas verdades esbarra na luta pelo poder sobre as pessoas e as coisas. Quanto mais poder, maior a sensação de imortalidade e perenidade na terra.

A cultura da violência religiosa tem seus atributos na construção de um poder que eterniza seus seguidores, mesmo pela sua autodestruição. O que se quer é ampliar seu poder espiritual e contestar o inimigo com sua força e poder de destruição.

De dominado pela angústia da morte passa-se então a seu senhor. O poder pode aparecer como bênção de imortalidade: na embriaguez do poder aninha-se a ilusão de matar a morte. Aqui, essencialmente, radica o vínculo fundamental entre religião, poder e, consequentemente, violência. Observa-se, de fato, na história das religiões, uma luta permanente no sentido de saber qual delas tem o Deus mais poderoso. (BORGES; 2010, p.27)

A divindade entra nesse contexto como o elemento supremo de notável poder e superioridade terrena e etérea. Assim o fundamentalismo religioso consegue justificar suas ações mais agressivas pela universalidade da busca do eterno, do supremo e, consequentemente, impor a possibilidade de dissolução de uma ordem estabelecida.

Essa ordem é vista a partir de um sistema que dá embasamento na organização social entre os povos e as nações, entenda-se aqui o modelo de organização da sociedade, o modo de viver e as relações estabelecidas entre as pessoas, além da forma econômica como as organizações atuam sobre o Estado. Uma vez que esta ordem está sob suspeita, é preciso garantir sua proteção e segurança. Justifica-se a apropriação do poder utilizando todas as formas de domínio ou, como afirmam os religiosos, libertando os povos da dominação.

O caminho da violência religiosa é o extremo de uma ação que começa de outra forma, pela doutrinação, pela formação e "educação" religiosa, ou seja, para libertar é preciso conhecer os preceitos sagrados da religião como verdade. Para adquirir força necessária é preciso conhecer as mais variadas técnicas de luta que passam pelo corpo a corpo, pelo conhecimento histórico/organizacional/militar, pelo autoconhecimento e também pelo amadurecimento psicológico de seus seguidores. 
Esse é um princípio de poder observável em diferentes lutas, das mais antigas às mais recentes, entre gerações diferentes ou mesmo profissões de fé políticas ou religiosas que se propõem antagônicas. Daí a universalidade e a relevância das descobertas psicanalíticas, não apenas como forma de tratamento de problemas emocionais, mas principalmente como ferramenta de compreensão do que há de irracional em algo racional no modo como o ser humano constrói e destrói valores, ora avançando, ora retrocedendo acerca de suas próprias concepções civilizatórias. (OLIVEIRA; 2005, p.32)

Esta concepção serve para mostrar que os muitos caminhos a trilhar quando o tema circunda o fundamentalismo, a religião, ou a ambivalência existente entre o amor e o ódio, a paz e a guerra, no contexto do poder e o sagrado. Pois, do ponto de vista psicológico, o fundamentalismo religioso tangencia discussões em torno da angústia e da ansiedade, que de alguma forma ameaçam o equilíbrio e a vida em grupo e sua coletividade.

Entretanto, é preciso compreender o preceito de início: onde começa ou quando começa um pensamento pautado no fundamentalismo religioso? Essa pergunta tem resposta simples, mas que merece algumas considerações. O fundamentalismo começa quando há qualquer sinal de intransigência religiosa. Quando a concepção de verdade se confunde com o termo posse, vai afirmar BORGES (2010)

Há várias explicações para o fundamentalismo, que cultiva o pensamento único e a intolerância. Sublinham-se três. 1 - Quando se não suporta viver na perplexidade e na interrogação, surge a tentação de absolutizar as próprias crenças, excluindo e perseguindo quem as não partilha. 2 - Em toda a História foi permanente a utilização da religião para fins que não são os seus: alcançar o poder, servir os próprios interesses econômicos, políticos, culturais, impor hegemonicamente o próprio domínio. 3 - Em última análise, na base está uma determinada concepção de verdade, que se confunde com a posse do Fundamento. Mas, precisamente aqui, é preciso perguntar: quem é o Homem, um ser finito, para considerar-se senhor do Fundamento? Ele não possui o Fundamento ou o Absoluto, é o Fundamento que o possui a ele. Isto não é relativismo, mas perspectivismo: vamos ao encontro da realidade sempre numa determinada perspectiva. (p.29)

A perspectiva aqui é mostrar que em pleno século XXI o fundamentalismo religioso não mudou seus preceitos, continua a trazer na intolerância a base de suas ações, tem na verdade

\footnotetext{
${ }^{30} \mathrm{~A}$ professora Maria Lúcia de Oliveira em sua obra "A rebeldia e as tramas da desobediência", no capítulo 3 intitulado: Rebeldia, obediencia e liberdade, faz uma reflexão a partir da obra de Freud - Totem e tabu (1968) - quando Freud afirma que a história da organização social tem sua gênese num levante contestador e revolucionário. Justifica a origem da sociedade conforme registros em diferentes culturas. Nelas a origem da vida em comunidade está condicionada à subversão da ordem. Nesse texto, subverter a ordem significa rebelar-se a partir de uma verdade religiosa estabelecida. Poderíamos partir para outros caminhos a fim de compreender aonde pode chegar o fundamentalismo religioso considerando a base de organização social de povos primitivos em relação às superstições e o respeito entre si.
} 
religiosa os princípios da posse e consequentemente a destruição do outro que não compreende ou não compactua com o seu pensamento.

O fundamentalismo enfrenta o mundo interpretativo do texto. Os livros sagrados são interpretados, analisados e conforme a interpretação as informações e modos de agir surgem como diagnósticos ou prognósticos para a sociedade.

A partir daí são informações, estratégias e interpretações para definir o que está sendo discutido no mundo e o que as escrituras sagradas têm a dizer sobre os mais variados assuntos. Nesse momento esgotam-se as experiências vindas da ciência, parte-se para a fé, talvez a metafísica consiga explicar tais fenômenos. Ação e discurso exigem compreensão nesse contexto.

\section{Considerações finais}

Hoje se vive a revolução da comunicação pautada nas diversas formas de conectividade, seja pelas informações via satélite, pelas conexões via internet, pelas informações em tempo real, além da possibilidade de fazer e acontecer a história que se vive e se mostra instantaneamente.

Esta era da comunicação em rede e busca pelo poder faz surgir novos conflitos armados, pois há investimentos na tecnologia, inclusive na área militar que funcionam como estratégias de Estado; o conceito de tempo é outro e o impacto sobre esse conceito é inevitável. Há uma convergência para uso das tecnologias da informação e comunicação e essa realidade é percebida pelos pesquisadores há mais tempo ainda. No caso do fundamentalismo religioso esse impacto é visível nas ações de caráter terrorista e gera mudança de comportamento imediato tanto no Estado como nos militantes religiosos que se preparam em meio aos desequilíbrios sociais e tecnológicos.

Nessa dinâmica mundial, Marc Augè (1994) chamaria de "superabundância factual”, ou seja, é possível dizer que a rapidez da tecnologia alinhada ao universo da comunicação torna o mundo cada dia menor e a história terá o papel principal de dar conta dessa agilidade em que se vive no século XXI. O maior problema desse frenesi é como acompanhar essa massa de acontecimentos transformados em "informação" e tentar compreender a efetivação da condição humana, seus preceitos de liberdade, sua pluralidade sem esbarrar em coisas que seriam humanamente incompreensíveis em outras épocas.

A "aceleração" da história corresponde de fato a uma multiplicação de acontecimentos, na maioria das vezes previstos pelos economistas, historiadores ou sociólogos. A 
superabundância factual é que constitui problema, e não tanto os horrores do século XX (inéditos por sua amplitude, mas possibilitados pela tecnologia), nem a mudança dos esquemas intelectuais ou as agitações políticas, dos quais a história nos oferece muitos outros exemplos. Essa superabundância, que só pode ser plenamente apreciada levando-se em conta, por um lado, a superabundância da nossa informação, e, por outro, as interdependências inéditas do que alguns chamam hoje de sistema-mundo, traz incontestavelmente um problema para os historiadores, principalmente os contemporâneos - denominação da qual a densidade factual das últimas décadas ameaça suprimir todo e qualquer significado. Mas esse problema é precisamente de natureza antropológica. (AUGE; 1994, p.31)

A exemplo dessa realidade apontada por Augè 20 anos atrás, hoje, as novas formas de conexões em tempos de comunicação móvel (mobile) permitem a criação de redes de comunicação praticamente em tempo real, e esse novo contexto de relação nos possibilita pensar que a busca pelo poder é constante e necessária. No fundamentalismo religioso, ela se torna ainda mais assertiva, potencializada e superabundante quando observada sob a ótica da possibilidade de conflito em qualquer lugar do planeta tendo as redes sociais, e suas formas instantâneas de comunicação, como maior aliada.

A simples possibilidade de tornar ações terroristas eventos midiáticos aumenta em proporção a cada dia, e dificulta o trabalho de segurança do Estado, pois o controle sobre essas redes é limitado. Essa fragilidade deixa a sociedade mais exposta, vulnerável a qualquer tipo de ataque.

Nesse início de século XXI pode-se afirmar que o ser humano está envolvido por um mundo físico, mas exposto a diversos canais de comunicação em suas redes interpessoais, o que vai determinar restrição ou ampliação no uso da informação que necessita.

As pessoas estão inseridas em campos de informação que determinam seu nível de consciência e conhecimento acerca de determinados assuntos. A natureza desses campos pode levá-las a encetar uma busca encadeada de informações e até mesmo determinar mudança de comportamento em certos aspectos. (JOHNSON; 2011, p. 169)

No caso do fundamentalismo religioso, isso tem acontecido, pois há interesse entre seus militantes de ampliar suas redes de comunicação e atuação, portanto, desencadear uma expansão em seu campo de informação.

O que significa isso? Aumentar o desejo das pessoas a procurar informação sobre seus preceitos, suas ações e ao mesmo tempo desenvolver novas interações para manter seus objetivos iniciais. 
Isso acontece pelo compartilhamento de informações que amplifica o espaço de ação, algo que as empresas e grandes organizações já fazem há muito tempo. Como afirma Johnson, há uma distribuição espacial do conhecimento, e a comunicação é um conceito um tanto quanto intangível, mas que precisa de interlocutores para se desenvolver.

Por fim, compreender o fundamentalismo nesse contexto é tentar abarcar as diferentes formas de interpretar a dimensão das religiões e suas diferenças, considerando seus aspectos conceituais, antropológicos, suas extensões históricas, sem deixar de fazer as devidas aproximações com a ordem social estabelecida no mundo.

\section{Referências Bibliográficas}

AGUILAR, Sérgio Luiz Cruz. Atentados de Paris. Revista Unesp Ciência. n.71, Fev. 2016 (Dossiê Paris)

AUGÈ, Marc. Não-lugares: introdução a uma Antropologia da Supermodernidade. São Paulo: Papirus, 1994 (Travessia do Século)

BORGES, Anselmo. Religião e diálogo inter-religioso. Coimbra - Portugal: Imprensa da Universidade de Coimbra, 2010. (Estado da Arte)

— Religião, religiões e diálogos inter-religiosos. Revista Portuguesa de História, n.40, 2008/2009. p. 07 - 44 Disponível em https://digitalisdsp.uc.pt/bitstream/10316.2/11961/3/01\%20-\%20Anselmo\%20Borges.pdf?ln=pt-pt

CASTELLS, Manuel. A sociedade em rede: a era da informação: economia, sociedade e cultura. trad. Roneide Venancio Majer. v.1, 2.ed. São Paulo: Paz e Terra, 1999.

DUPAS, Gilberto. Atores e poderes na nova ordem global: assimetrias, instabilidades e imperativos de legitimação, 2005.

. Ética e poder na sociedade da informação. 2.ed. São Paulo: Editora Unesp, 2000.

HOLLANDA. Sérgio Buarque de. Raízes do Brasil. 12.ed. Rio de Janeiro: José Olympio, 1978.

HOBSBAWN, Eric. Era dos extremos: o breve século XX (1914 - 1991). 2.ed. São Paulo:

Companhia das Letras, 2003.

JOHNSON, J. DAVID. Gestão de redes de conhecimento. Trad. Janaína Marcoantonio. São Paulo: Editora Senac. 2011. 
OLIVEIRA, Maria Lúcia. A rebeldia e as tramas da desobediência. São Paulo: Editora Unesp, 2010. (Coleção paradidáticos)

RODRIK, Dani. A globalização foi longe demais? São Paulo: Editora Unesp, 2011.

SAINT-PIERRE, Héctor Luis. O conceito de terrorismo. Jornal da Unesp, maio/2016. Caderno Fórum - $\mathrm{O}$ terrorismo e sua sombra. 